\title{
A didática da improvisação musical na escola primária e secundária ${ }^{1}$ : Perspectivas teóricas e diretrizes de método
}

\section{VINCENZO CAPORALETTI²}

Resumo. Os estudos sobre improvisação musical tiveram notável florescimento recente, especialmente na Itália. Não poderia ser diferente, creio que se possa afirmar, na terra dos poetas improvisadores da rima oitava e do partimento setecentista, apesar da proclamada primogenitura ultramarina, jazzística ou não. Mas o aspecto que mais se destaca aqui é que essa nova onda de pesquisas não poderia deixar de repercutir na finalidade eletiva da investigação teórica, com a aplicação, ou melhor, a transposição pedagógico-didática. Neste artigo, analisarei algumas direções didáticas já estabelecidas, verificando suas conexões com modelos teóricos de criatividade em tempo real hoje desafiados por essas pesquisas recentes. Outras propostas operacionais se seguirão à luz da convicção de que uma mudança no paradigma teórico implica necessariamente um reposicionamento das estratégias educacionais e didáticas.

\section{Introdução}

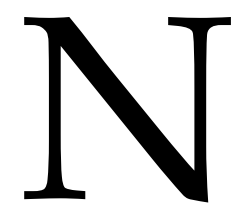

a $22^{\text {a }}$ rapsódia da Odisseia, em uma cena de grande pathos em que Odisseu está prestes a matá-lo, o aedo Femio se utiliza de uma imagem icônica para definir sua própria essência criativa e assim induzir o herói a poupá-

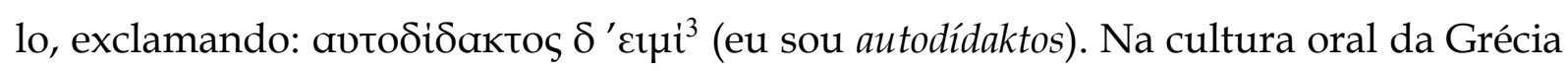
antiga, Femio representa, portanto, o símbolo desses valores de criatividade extemporânea e espontânea que ainda hoje atribuímos a práticas de improvisação, a concepção/realização ex tempore: ele, portanto, se refere à sua própria habilidade de

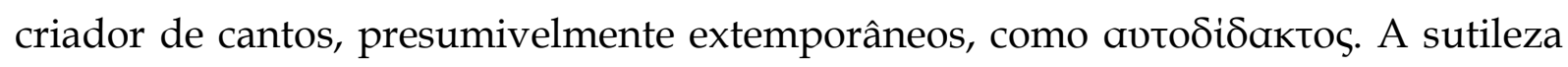
crítica do filólogo Walter Belardi nos mostrou como este termo não corresponde absolutamente à noção contemporânea de nosso "autodidata" e também não implica

\footnotetext{
${ }^{1}$ No sistema educacional italiano, ao qual o autor se refere, o ensino básico é dividido em escola primária (dos 6 aos 10 anos de idade) e secundária (dos 11 aos 18 anos de idade). (NdT).

${ }^{2}$ Artigo publicado em duas partes na revista Musica Domani, publicação semestral da SIEM (Società Italiana per l'Educazione Musicale); a primeira no número 174, de junho de 2016, (p. 50 a 61) e a segunda no número 175, de dezembro de 2016, (p. 31 a 37). Tradução de Luiz Santos-Lima UNICAMP luizlima1611@gmail.com

${ }^{3}$ Odisseia, canto XXII, v. 347.
} 
na lição clássica, posterior, para a qual esses cantos improvisados seriam inspirados por uma divindade, uma Musa.

O que, portanto, Femio ressalta de si mesmo, como uma coisa singular que tem algo de prodigioso, é seu "conhecimento espontâneo", que imediatamente coloca o possuidor fora da ordem comum dos mortais, cujo conhecimento, diversamente, é mediado. (BELARDI, 1990, p. 228).

Pretendo por acaso com isso argumentar que as práticas da improvisação não possam ser ensinadas? Elimino a possibilidade de tais equívocos, negando categoricamente esta posição. À luz das indicações e sugestões anteriores, tratar-se-ia, ao contrário, de reconstituir em uma pedagogia da improvisação aquela presciência incorporada, ${ }^{4}$ de fazer ressurgir maiêuticamente aquelas predisposições comuns às faculdades criativas em tempo real que correm o risco de obsolescência no amadurecimento pessoal e/ou o turvamento no percurso educacional.

\section{Uma pedagogia da improvisação?}

Mas quais estratégias adotar e a que critérios epistemológicos se referir para uma orientação pedagógica voltada à promoção e ao uso profícuo das habilidades improvisativas? Antes de tudo, é necessário esclarecer o quadro metodológico em que se coloca o problema da pedagogia e do ensino dos processos improvisativos (em relação à infância, mas não apenas). Pelo menos três perspectivas de pesquisa podem ser diferenciadas:

1. práticas criativas em tempo real entendidas como finalidade pedagógica/didática (isto é, aprender a chamada "improvisação musical") em função de determinados estilos e gêneros em que é constituinte formativo preponderante (me refiro ao jazz, ao rock, às tradições musicais não ocidentais: é o estudo da improvisação musical da maneira como é conduzida nos conservatórios de música e escolas de jazz);

4 Essa noção de "presciência" consona com a concepção de conhecimento em Heidegger, como interpretação subsequente (Auslegung) de uma compreensão originária em que as coisas são para nós, desde sempre, já descobertas. 
2. práticas criativas em tempo real entendidas como meio (improvisar para adquirir aptidões e competências musicais ou de natureza educativa mais geral: este âmbito se adéqua mais propriamente à didática da escola dentro do ensino obrigatório); ${ }^{5}$

3. considerar a própria improvisação infantil, tomada em si mesma, como objeto de estudo (é um campo de pesquisa relacionado à psicologia infantil, da qual temos atestados científicos em uma abundante literatura: Moorhead e Pond (1941-1951), Flohr (1979), Kratus (1991), Mialaret (1997), Miroudot (2000), apenas para citar alguns: ver referências bibliográficas).

Ora, na presente discussão, concentrar-me-ei principalmente na segunda área de pesquisa, no ensino da improvisação musical como meio, como vetor de um processo de formação mais amplo (mas a perspectiva de reflexão também afetará o aspecto específico "técnico" do ensino da improvisação como finalidade autônoma, como se verá, dado que os dois objetivos não são disjuntos).

Antes de iniciar a discussão, porém, é preciso especificar um aspecto fundamental de minha abordagem a estas problemáticas. A experiência de décadas como professor de "improvisação musical" em vários contextos (da escola obrigatória aos cursos de iniciação musical, dos conservatórios de música à universidade) convenceu-me de que muitas metodologias em uso e muita literatura especializada são invalidadas por uma vulnus original. Este núcleo não resolvido no plano teórico, e consequentemente metodológico, frequentemente se torna o fator de impedimento que se configura na prática - e aqui me refiro aos cursos de improvisação jazzistica como divisor de águas entre a experiência de alunos que conseguem chegar a práticas realmente eficazes e intencionais de criatividade improvisativa (frequentemente alcançando isso, é preciso mesmo dizer, graças a percursos independentes de aprendizagem) em comparação com aqueles, especialmente se provêm de uma disciplina acadêmica de estudo instrumental, que não conseguem adquirir essas habilidades específicas.

A sabedoria pragmática dos professores de improvisação, muitas vezes irremovivelmente ancorada àquela forma de sabedoria não discursiva que se define

\footnotetext{
${ }^{5} \mathrm{O}$ ensino obrigatório na Itália compreende o $1^{\circ}$ ciclo de instrução - escola primária (dos 6 aos 10 anos de idade) e secundária do primeiro grau (dos 11 aos 13 anos de idade), e os dois primeiros anos do $2^{\circ}$ ciclo de instrução (escola secundária do segundo grau - dos 14 aos 18 anos de idade). (NdT)
} 
como "conhecimento tácito", desde sempre resumiu esta complexa questão em uma frase icônica, para a qual - referindo-se neste caso ao blues - "Ninguém jamais conseguirá tocar uma frase partindo do estudo da escala de blues". Ou seja, em termos mais formais, nunca se chegará à aquisição concreta de habilidades improvisativas estilisticamente orientadas a partir das regras derivadas de uma formalização sistemática (assim como se encontra em um manual de teoria musical para uso improvisativo). Ora, essa enunciação contém uma verdade transcendente, mas ao mesmo tempo disruptiva, que por si só tem o potencial de invalidar grande parte da literatura - estou falando de milhares de textos - dedicada ao ensino de práticas improvisativas; aliás, compromete o próprio modelo de transmissão de conhecimento, estrutural na formação não só da música ocidental, baseada na utilização de um "manual" e na transmissão teórica de "regras" relativas a um sistema "fechado" e autorreferencial (pensemos no estudo da harmonia clássica).

A ideia de fundo que pretendo defender nesta contribuição é que, para se obter resultados válidos na prática pedagógica da criatividade extemporânea, para aproximar concretamente os neófitos a este vasto horizonte de práticas criativas (e me refiro tanto aos alunos da escola primária e secundária quanto a músicos especializados que estudam "improvisação musical"), é necessário repensar radicalmente a natureza do processo de improvisação em si. Para esta revolução copernicana, será necessário um esforço de análise dos próprios fundamentos da imagem atual dos processos improvisativos ${ }^{6}$ para fazer uma "desconstrução" e uma possível refundação sobre novas bases. Este procedimento orientará, no nível das transposições didáticas, na direção de determinadas estratégias coerentes com as novas abordagens teóricas, baseadas em critérios didáticos que já revelaram a sua efetiva eficácia e funcionalidade.

Para ajustar o discurso em uma perspectiva operacional clara, é oportuno antes de tudo:

\footnotetext{
${ }^{6} \mathrm{Na}$ realidade, neste artigo não descreverei em detalhes essa reformulação de paradigma, pois ela foi objeto de uma discussão específica em Caporaletti (2005), a que, obviamente, remando; aqui, darei algumas indicações gerais, a fim de orientar adequadamente a argumentação para fins didáticopedagógicos.
} 
1. examinar criticamente exemplos de metodologias didáticas de improvisação (no caso em questão, uma proposta dirigida especificamente aos alunos da escola primária) e verificar os seus eventuais limites;

2. estabelecer se esses limites são compartilhados pelos modelos de abordagem conceitual da improvisação em cursos especializados, mesmo em nível de conservatório.

A metodologia que vou tomar em consideração, IBIS (Insegnare ai Bambini ad Improvvisare con gli Strumenti - Ensinar as crianças a improvisar com os instrumentos) foi proposta por Johannella Tafuri e Gabriella Baldi (TAFURI, 2006). Um propósito significativo deste projeto configura-se na verificação do grau de congruência entre entregas, ou seja, a atribuição de tarefas pelo professor e realizações improvisativas. Tais entregas são definidas com base em três tipologias diferentes.

a) Entrega semântica (restrição descritiva: convida-se a improvisar inspirando-se em uma história, uma imagem).

b) Entrega sintática (vínculo formal): com base nos princípios gerais da Gestalt (repetição; contraste; alternância; intensificação; intensificação/diminuição; frases; variações; simetria).

c) Entrega ad libitum.

Uma avaliação crítica desta metodologia não pode deixar de reconhecer a rigorosa coleção dos dados e sua elaboração em termos de estatística, com procedimentos verificados que conduzem a resultados de indubitável interesse. O que, no entanto, suscita perplexidade é a incongruência desse feroz aparato operacional com o objetivo declarado em nome do próprio projeto (ou seja, ensinar as crianças a improvisar com instrumentos). De fato, um nó problemático bastante grave é dado pelo fato de na IBIS a capacidade de improvisação ser assumida como uma faculdade já adquirida de várias formas, como uma competência da qual se predispõe e da qual é possível avaliar os investimentos concretos em relação às entregas indicadas. Mas, deixando de lado aqui um exame objetivo da metodologia e os problemas específicos 
de transposição didática que ela suscita, cabe destacar a criticidade na orientação básica que a subjaz à luz do horizonte epistemológico de referência em que se subentende a noção de "improvisação musical" (vimos como explicitar criticamente esta categoria de fundamental importância, uma vez que nos direciona para modelos teóricos alternativos e orientações didático-operacionais diversificadas, baseadas em novos pressupostos).

Nesse sentido, o modelo IBIS é baseado em uma concepção de prática improvisativa fundamentalmente entendida como a implementação/articulação de estruturas abstratas do tipo descritiva ou formal (é com base nestas, de fato, que a improvisação é avaliada em termos de originalidade criativa e classificada de acordo com as tipologias operacionais adotadas). Nesse sentido, portanto, não revela uma especificidade metodológica em função da criação em tempo real, de tal maneira que é igualmente substituível para o estudo da composição musical, não revelando traços diferenciais (aliás, a atividade prefigurada de elaboração de um artefato improvisado não representa o modo como 99\% das culturas musicais operam em tal sentido). Isso, no que concerne ao ensino de práticas criativas em tempo real para crianças. E em relação às finalidades especializadas, nos cursos de técnica de improvisação, inclusive nos conservatórios? Pois bem, creio que em muitos casos os aspectos problemáticos já apontados, curiosamente, se repropõem inalterados, por meio da mediação teórica de uma complexa série de regras que reconduzem a improvisação a uma questão de elaboração de estruturas abstratas, nem mais nem menos que a composição escrita. Frequentemente quem afronta a improvisação jazzística a partir da teoria, assim como normalmente acontece com o estudo da harmonia ou da composição na formalização didático-pedagógica tradicional - portanto mediante estratégias, digamos, voltadas à aprendizagem de estruturas escalares -, gera inconscientemente um outro infeliz tópos, corolário do que já foi observado para a escala de blues. Nesta conjuntura, o aluno diligente, após um período adequado de estudos, encontra-se a contragosto como expoente da temida casuística de quem, sempre no jargão didático, "pode fazer centenas de escalas, mas sequer uma frase jazzística". Na melhor das hipóteses, o disposto aprendiz, com esforços indizíveis, pode se reposicionar na casuística, ocupando a posição de quem "consegue repetir de cor alguma frase, mas sem o menor 
swing". O aspecto mais amargo desse processo didático talvez seja que o próprio aluno percebe, muitas vezes só depois de anos, a lacuna intransponível entre as intenções e os resultados em suas próprias habilidades performativas, experimentando em sua própria pele a inanidade de um estudo louco e desesperado sobre escalas e acordes.

Retorna-se sempre ao ponto central: o uso de critérios improvisativos em função linguístico-criativa. Tanto no método IBIS, destinado a crianças do ensino primário, como nos cursos de improvisação para músicos experientes existe o (inconsciente?) pressuposto de que as estruturas abstratas devem constituir a (única? Fundamental?) espinha dorsal do processo didático.

\section{Algumas questões epistemológicas}

Essas observações levantam pelo menos dois tipos de problemas no nível epistemológico que precisam ser esclarecidos imediatamente:

1. O que a noção de "estrutura abstrata" significa neste contexto?

2. Em que sentido o conceito de composição é contrastado com o de improvisação?

No que diz respeito à questão das "estruturas abstratas", pode-se aplicar à metodologia IBIS (e, sob outros aspectos, aos manuais de técnica de improvisação) a crítica que Michel Imberty (2003) dirige à teoria gerativa de Lehrdal e Jackendoff (1983).

[Com este gerativismo] se trata basicamente de saber como se produzem as estruturas, e não como a criança, e mesmo o adulto, produz uma música que pode ter uma originalidade própria, que possua um dinamismo próprio mais essencial do que as combinações de sons e durações descritas pelas regras de gramática. (IMBERTY, 2003, p. 101). ${ }^{7}$

\footnotetext{
7 Original: "[Avec ce generativisme] il s'agit en gros de savoir comment se produisent des structures, et non commel'enfant, voire l'adulte, produit de la musique qui peut avoir son originalité propre, qui possède son dynamisme plus essentiel que les combinaisons de sons et de durées décrites par les règles des grammaires" (IMBERTY, 2003, p. 101).
} 
Pessoalmente, vejo esse "dinamismo" gerado por um processo cognitivo e poiético, que chamo de "audiotátil", e as regras de gramática, por outro lado, mediados por uma cognição que defino epistemologicamente "visual" (ver CAPORALETTI, 2000, 2005, 2007, 2008, 2011a, 2011b). A questão se esclarece de maneira evidente no momento em que se faz referência a repertórios em que o dinamismo se concretiza em formas precisas de organização da temporalidade musical em função sensório-motora, gerando sistemas correlacionados de valores estéticos altamente pertinentes, organizados em sistemáticas (etno)teóricas com taxonomias muito refinadas. Refiro-me, para as músicas propriamente audiotáteis, às noções êmicas de swing, groove, drive, flow, de atitude propulsiva/depulsiva etc. (no jazz e rock); ou, em músicas baseadas na formatividade audiotátil, ${ }^{8}$ aos conceitos de laya na música do Hindustão, de rèpriz ou lokans em Guadalupe, de balanço na música afro-brasileira etc. (ver CAPORALETTI, 2000, 2005). Essas noções incorporam aquela mais geral de coerência improvisativa fraseológica, que depende dessas formas especificamente conotadas de articular a temporalidade. ${ }^{9}$

Para aprofundar a questão, analisemos a posição de Jean Molino (1998), que coloca na base do desenvolvimento da cultura ocidental uma tensão dialética entre a ontologia dos objetos e a ontologia dos eventos (dicotomia que, aliás, apresenta analogias precisas com a das funções cognitivas visuais e audiotáteis propostas por mim). Em particular, com referência à aplicação à música deste par opositivo, Molino afirma:

A música não diz respeito apenas ao som, se trata, ao invés, de som transformado pela experiência humana... A música não se baseia em notas, escalas ou regras de sucessão harmônica, mas em esquemas que combinam o som com o perceptivo, o motor, o afetivo. (MOLINO, 1998, p. 264). ${ }^{10}$

\footnotetext{
8 Para a distinção entre "músicas propriamente audiotáteis" e "músicas fundadas sobre formatividade audiotátil", ver Caporaletti (2004).

${ }_{9}$ Obviamente, aqui estamos nos referindo a códigos improvisativos específicos baseados em estilos, como o bop ou o jazz modal, que constituem o cânone de referência mais compartilhado dos cursos de improvisação jazzistica. Para as problemáticas relacionadas às práticas alternativas a esses estilos, como, por exemplo, a free music europeia, o neo-tonalismo ou a improvisação no contexto da Música Nova de tradição acadêmica (CAPORALETTI, 2005).

${ }^{10}$ Original: “La musique ce n'est pas seulement du sonore, c'est du sonore transformé par l'expérience humaine... La musique ne se fonde pas sur des notes, des échelles ou des règles de succession
} 
Eis que se nos apresentam elementos mais precisos para enquadrar o "paradoxo da escala de blues" a que me referi. A impossibilidade de formular repentinamente uma frase musical, estilisticamente conotada, a partir de uma estrutura abstrata (a escala de blues) não é imputável necessariamente a deficiências individuais, mas a um fator intrínseco e inevitável. Ou seja, em quanto tal "frase", no contexto improvisativo, se concretiza e revigora exatamente em função daqueles "esquemas motores e afetivos" de que fala Molino, ou - em outros termos - do "dinamismo" de Imberty, ou ainda do som (humanamente) organizado conforme os endereços audiotáteis de tipo sensório-motor que expliquei: todos fatores de procedimentos que a "estrutura abstrata" simplesmente não pode veicular. O problema adquire um relevo desastroso na música improvisada justamente pelo fato de que esses fatores são, como já disse, altamente pertinentes e que, se suprimidos, perde-se totalmente o sentido de fazer música aliada à sua reconhecibilidade e legitimação cultural.

Os sons, portanto, não são substâncias, mas eventos caracterizados por continuidade. ${ }^{11}$ Ao ouvir um som, não nos deparamos com uma res circunscrita, visível e delimitada (Heidegger diria "presença-simples": Vorhandenheit), mas somos orientados pela percepção a nos questionarmos sobre a causa desse processo sonoro, sobre o ser que o determina. Esse fenômeno revela-se pleno de implicações simbólicas na particular síntese cognitiva promovida pela mediação cognitiva psicossomática que chamo de audiotátil, constituída em si mesma na pura processualidade da continuidade. $\mathrm{O}$ discreto, o elemento estrutural constitutivo, na música, não é outra coisa senão o artefato abstrativo do pensamento humano que separa e analisa a partir de realidades objetivas e não eventuais, fora do contexto subjetivo e vividas no curso temporal. Esse processo de segmentação e objetivação - segundo códigos teóricomusicais que, por sua vez, derivam, na música escrita ocidental, de uma concepção cartesiana, racionalizadora e geometrizante da percepção e da sensação - remonta à noção de theory ladenness of observation do filósofo Norwood Russell Hanson

\footnotetext{
harmonique mais sur des schèmes qui mêlent au sonore le perceptif, le moteur, l'affectif" (MOLINO, 1998, p. 264)

${ }^{11}$ Essa concepção é bastante presente em Meyer (1973), lá onde a estrutura melódica é concebida, ao mesmo tempo que contorno, desenho, como dinamismo, força orientada.
} 
(CAPORALETTI, 2005, 2008, 2011b). A carga teórica, neste caso, é o meio que nos faz articular a forma sonora segundo conceitos e modelos (acordes, tonalidades, escalas, critérios formais, de condução contrapontística etc.) completamente ausentes em outras modalidades perceptivas de músicas não carregadas teoricamente, tais como as das crianças ou do público não alfabetizado musicalmente, ou de culturas "outras" (que, de fato, têm modos alternativos - audiotáteis - de perceber e organizar a forma sonora).

A perspectiva audiotátil pretende, portanto, reintroduzir a temporalidade da subjetividade existencial nas estruturas, que não renega, em todo caso, a priori. Toda a história do jazz, aliás, atesta a abundância de investimentos estruturais de músicos improvisadores - em particular definidos por complexos critérios harmônicos e escalares e de elaboração motívico-temática - dentro de uma ordem procedimental, porém idiomaticamente implantada na fenomenologia do swing e do groove.

Esse discurso nos remete diretamente ao outro grande problema epistemológico, a relação entre composição e improvisação: para definir corretamente essa problemática, devemos verificar como o processo improvisativo é representado na literatura científica atual.

Bruno Nettl (1974) propôs uma modelagem da improvisação musical como uma composição rápida. Nessa representação epistemológica dos processos improvisativos, eles são tratados, podemos dizer, como coplanares aos processos composicionais. Os dois processos são vistos como duas faces da mesma modalidade fenomenológica "composicional" e se diferenciariam apenas em função do parâmetro temporal, dependendo se o ato composicional é "lento" (slow composition = composição escrita) ou "rápido" (rapid composition, na improvisação, na ação em tempo real que não permite reversibilidade no tempo) (ver Fig. 1). 
Figura 1: Representação da "concepção coplanar" de Nettl do processo de improvisação

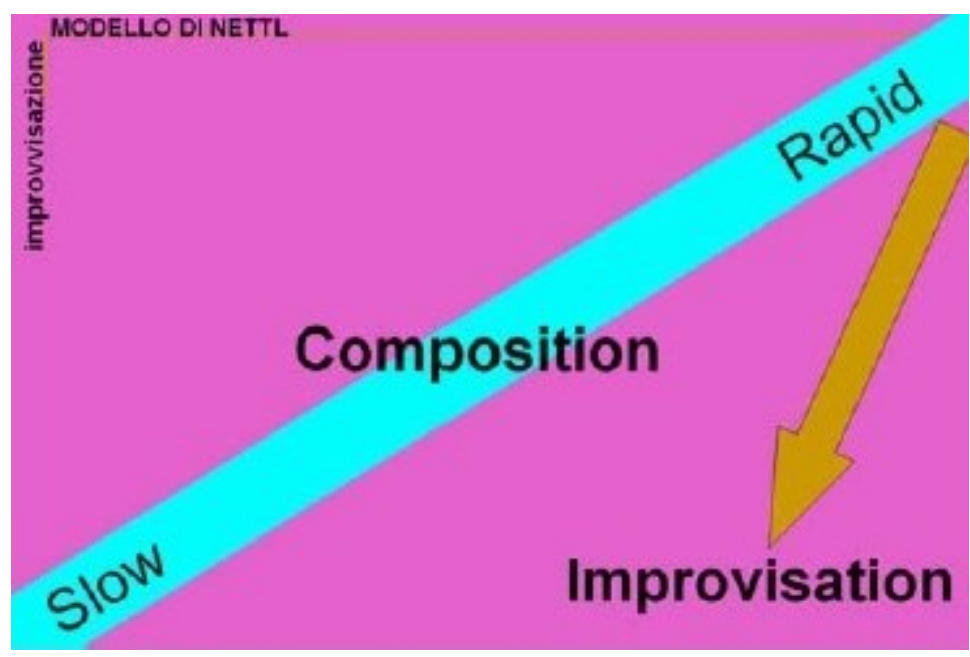

Os limites desta concepção coplanar se evidenciam fundamentalmente em razão de duas objeções fundamentais:

1. A noção de composição não pode ser considerada universal, com valor intercultural;

2. Nos dois tipos de práxis - composicional e improvisativa - atuam diferentes formas cognitivas que marcam os resultados de forma mutuamente irredutível.

Essas objeções estiveram na base do meu tratado Os processos improvisativos na Música: uma abordagem global (CAPORALETTI, 2005). Partindo exatamente da crítica ao modelo "coplanar", cheguei à teorização de uma nova representação dos processos improvisativos e à identificação de conceitos inovadores, como o da extemporização, que segue lado a lado à improvisação propriamente dita (portanto, é uma obra à qual aqui necessariamente remeto). Nesse sentido, darei a seguir apenas algumas indicações gerais, de modo a poder chegar à questão das consequentes transposições didáticas que podem ser extraídas dessas perspectivas inovadoras. 


\section{O modelo improvisativo na teoria audiotátil}

No que se refere à questão da noção de composição, entendida como universal, é fácil mostrar como nem todas as culturas do mundo contemplam ou contemplaram este conceito, que, aliás, se configurou relativamente tarde mesmo dentro da cultura ocidental (CAPORALETTI, 2005, p. 116 et seq.). Não é produtivo, portanto, utilizar como invariante gnoseológica o conceito de "composição" para definir um outro em si, tendo em vista o fato de que os processos improvisativos são ativos nas músicas de bens culturais que não (re)conhecem essa noção.

Como alternativa à dicotomia composição/improvisação em Caporaletti (2005), propus uma teorização dos processos de criação ex tempore que prescinde desta oposição conceitual e do intrusivo conceito theory-laden e etnocêntrico de "composição", representando o processo improvisativo só em função do princípio audiotátil (PAT) e do modelo específico de formatividade que ele promove. Evitando um frequente mal-entendido, chamo atenção ao fato de que o PAT não deve ser confundido, simplesmente, com o "corpo" do intérprete, uma vez que toda música (mesmo a da tradição escrita ocidental) é realizada por meio do movimento corporal que gera o som. O PAT é, ao invés, o medium psicossomático como formador de experiência, como indutor de um modelo particular de cognição, de uma condição de pensabilidade/instanciabilidade da forma sonora organizada. Na verdade, ele atua na dimensão principalmente poiética da criação musical, e não - referindo-se à peculiaridade alográfica ${ }^{12}$ da música culta ocidental - na execução de uma partitura composta de acordo com uma concepção irrevogável do texto musical. Como um plexo psicossomático não compreendido em sua identidade puramente material, mas como um medium que condiciona e direciona os resultados perceptuais e cognitivos, o PAT se imprime, portanto, em função do seu próprio sistema operacional, sua própria lógica orgânica interna, as faculdades cognitivas e a imaginação musical. Sua funcionalidade se contrapõe àquela promovida pelo medium dado pela dualidade notação musical/teoria musical ocidental (que possui um sistema operativo diferente, baseado em critérios epistêmicos de linearidade, sequencialidade, segmentação da

\footnotetext{
${ }^{12}$ Cf. Goodman (1968).
} 
experiência, repetibilidade uniforme, dentro de uma ordem abstrativa e matematizada relativa a um generativismo sintático-combinatório (ver, pelo menos, CAPORALETTI, 2005, p. 69 et seq.).

Nessa perspectiva, os processos criativos em tempo real não são vistos em relação à noção de composição, mas como uma projeção da atividade formativopersonalizadora do PAT em larga escala temporal, no processo macroestrutural organizativo-ideativo do material sonoro. Essa prospecção vetorizada da enérgeia poiética do PAT na dimensão temporal revela um interessante efeito de autossimilaridade com a ação dirigida pelo próprio PAT na microestrutura temporal, cruzando a linha do tempo verticalmente, na intersticialidade de 15-20 milissegundos, quando gera aqueles fatores sensório-motores que a tradição do jazz e do rock chamou de swing, groove, drive ${ }^{13}$ (ou as discrepâncias participativas de Charles Keil). ${ }^{14}$ Nesse sentido, poderíamos dizer que a improvisação é o fenômeno do swing (e do groove) que torna a organização sonora em larga escala, em um processo de natureza fractal. Da mesma forma, as faculdades mnemônicas envolvidas são complementares: a memória de médio/longo prazo ativa nos processos criativos em tempo real em relação à memória ecóica, que atua na microestrutura temporal que preside o swing (ver Fig. 2).

Fig. 2: A projeção da formatividade audiotátil em larga escala temporal induz à processualidade improvisativa

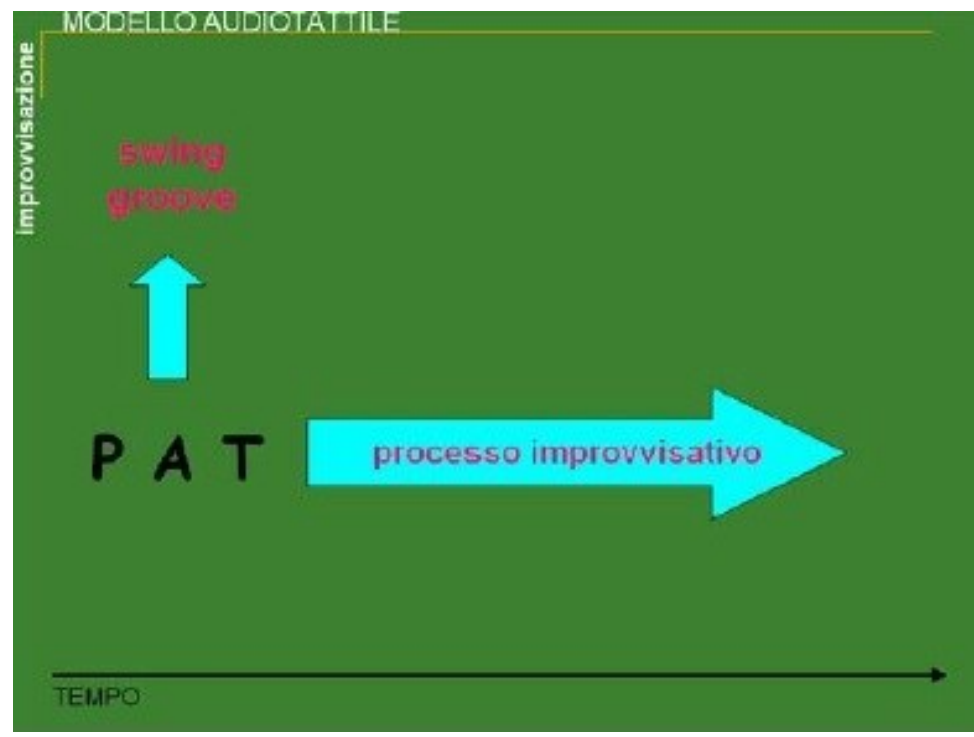

13 Cf. Caporaletti (2000).

14 Cf. Kell (1987). 
Chegamos agora à segunda objeção, que diz respeito às funções psicocognitivas que diversificam os dois modelos de criatividade, compositiva e improvisativa. Em primeiro lugar, é preciso notar como a composição da tradição musical escrita ocidental está genética e epistemologicamente localizada dentro do que Molino (1998) define por ontologia do objeto e faz uso de estruturas (conceitos, técnicas, procedimentos compositivos) colocadas em uma ordem temporal congelada e espacializada, de matriz epistemológica visual. Revela-se, portanto, uma questão de crucial relevância para os fins de nossa discussão: estabelecer a possibilidade de diferentes faculdades psicocognitivas que guiariam, caracterizando-as, por um lado, para a experiência visual, da ontologia do objeto e, por outro, para a experiência audiotátil e eventual.

No plano psicológico/cognitivo, Imberty (2003) diferencia os esquemas de ordem e os esquemas de relação de ordem, ativos psicocognitivos que se referem a experiências musicais em geral, mas que considero esclarecedoras exatamente por causa da dicotomia entre as categorias visual e audiotátil. Pode-se afirmar, de fato, que os esquemas de ordem são fundamentalmente estranhos à experiência visual da composição escrita da tradição clássica/romântica/modernista e que a formatividade audiotátil, embora eletivamente seja baseada nestes últimos, prevê a utilização de ambos os esquemas.

Mas vamos ver em que consistem esses diferentes esquemas psicocognitivos.

Os esquemas de ordem constituem o conjunto de intuições que o sujeito tem das sequências temporais sem que ele tenha consciência dos elementos constitutivos dessas sequências. Trata-se, portanto, de intuições de natureza sensório-motoras ou representacionais cujos conteúdos são indissociáveis das próprias sequências ordenadas. (IMBERTY, 2003, p. 103)..$^{15}$

A esta altura, podemos corretamente sustentar que os esquemas de ordem são a base psicocognitiva desses plexos procedimentais formais, altamente relevantes

\footnotetext{
15 Original: "Les schèmes d'ordre constituent l'ensemble des intuitions que le sujet a des successions temporelles sans qu'il ait conscience des éléments constitutifs de ces successions. Il s'agit donc d'intuitions de nature sensorimotrices ou représentationnelles dont les contenus sont indissociables des séquences ordonnées elles-mêmes" (IMBERTY, 2003, p. 103).
} 
em certos repertórios, aos quais me referi (o fenômeno do swing, groove etc., veja acima).

Os esquemas de relação de ordem organizam a lógica da sequência em um tempo recipiente independente dos eventos contidos. Cada evento, por exemplo, cada nota ou acorde, vê sua própria posição definida em relação ao conjunto de outros eventos, ou seja, por meio de uma sintaxe. (IMBERTY, 2003, p. 103). ${ }^{16}$

Essas distintas faculdades dos esquemas de relação de ordem orientam, pelo contrário, uma maneira preeminente para a funcionalidade visual que é eletivamente expressa na composição escrita da tradição culta ocidental.

Ainda em relação às neurociências, ocorre de essas faculdades serem acompanhadas pelo horizonte epistemológico inaugurado pela pesquisa sobre o chamado sentido da ação, a partir das descobertas sobre os mirror neurons (neurônios espelho), que reformulam as relações entre percepção, cognição e habilidades motoras, prefigurando um estatuto psicomotor da experiência sonora (ver CAPORALETTI, 2005, p. 84 e referências bibliográficas).

Junto com a representação epistemológica dos processos improvisativos como projeção da formatividade audiotátil na grande escala formal/temporal e a função psicocognitiva dos esquemas de ordem e esquemas de relação de ordem (e dos neurônios espelho), existe, finalmente, outro aspecto que contribui para a modelagem teórica dos processos improvisativos. Refiro-me à inovadora categoria da extemporização, introduzida em Caporaletti (2005, p. 98 et seq.), que mencionarei brevemente, precisamente pela importância crucial que ela assume, aqui, para efeitos da transposição didática do modelo teórico.

No quadro da minha representação dos processos improvisativos na música, esta noção identifica uma classe de práticas de criação em tempo real que se diferencia da improvisação propriamente dita (deste ponto de vista, portanto, os processos improvisativos, ou melhor, os procedimentos de criação em tempo real, compreendem seja critérios extemporizativos, seja improvisativos). Por uma questão

\footnotetext{
16 Original: "Les schèmes de relation d'ordre organisent la logique de la succession dans un temps contenant indépendant des événements contenus. Chaque événement, chaque note ou accord par exemple, voit sa place définie par rapport à l'ensemble des autres événements, c'est-à-dire par une syntaxe" (IMBERTY, 2003, p. 103).
} 
de brevidade e a título de citação, apresento a seguir uma sucinta descrição, sempre remetendo ao aprofundamento do texto de referência e seus argumentos detalhados.

\section{Fig. 3: Esquematização do processo extemporizativo}

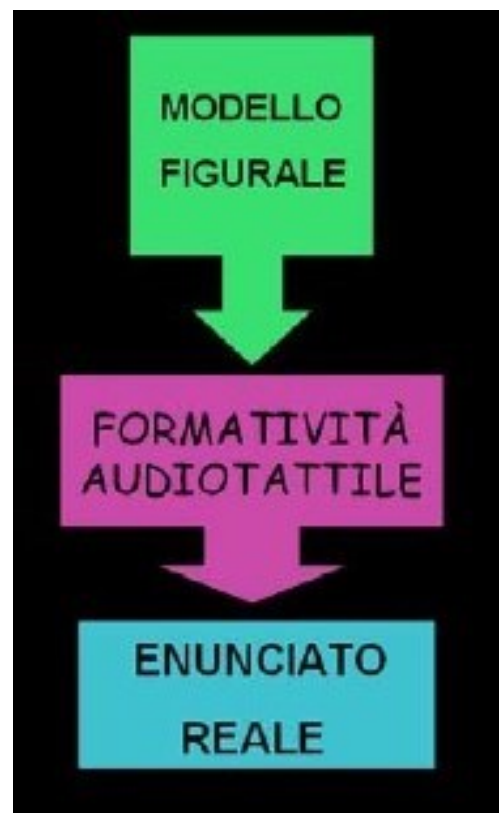

A extemporização é um processo criativo em tempo real que pode, em linha geral, ser representada como uma direta instanciação sonora de uma unidade de conceituação musical - de um modelo, de consistência imaginativa - por meio do filtro da formatividade audiotátil; o enunciado real resultante é consequentemente constituído como texto. ${ }^{17}$ Em outras palavras, ela pode ser entendida como uma tipologia da prática ex tempore - que objetivamente, no plano ético, é criada instantaneamente, portanto, num certo sentido, "improvisada" - que dá origem a um texto identificável, a uma peça específica e delimitada, e não a um processo variacional ou elaborativo intencional e culturalmente reconhecido. As ocorrências são múltiplas: do canto ritual em culturas tradicionais aos procedimentos de harmonização e ritmização em uma canção do tipo pop ou jazz, à própria exposição melódica em uma peça de jazz ou pop, à paráfrase do tema no jazz, às estratégias de correção in itinere de defasagens na conduta métrica de um grupo, etc.

\footnotetext{
${ }^{17}$ Nesse sentido, concordo com as posições de Fabrizio Della Seta (2011), na hipostatização, alargamento e fungibilidade da noção de texto dentro de uma sistemática geral dos fenômenos musicais.
} 
Do ponto de vista formal, portanto, tal texto estará livre de elaborações contextuais sistemáticas e intencionais que pressupõem a introdução de novo material, como projeção do mélos individual, com base em critérios de originalidade criativa, autonomia estética e contemplação desinteressada por parte do público. Embora desprovida de um cota específica de improvisação, no sentido variacional-elaborativo, este enunciado textual (peça musical, mas também poética, dramatúrgica, etc.), pelo seu próprio ser vertido ex tempore e dependente de uma conceituação não pré-escrita ou de memorização, é de qualquer maneira o resultado de um procedimento de criação em tempo real, no qual a variante, por meio da formatividade idiossincrática audiotátil, torna-se um processo constitutivo intrínseco ("variante" entendida em relação à mesma unidade conceitual que atua como modelo).

Em todo caso, é importante estabelecer que a extemporização não é simplesmente uma variante expressiva do texto, como a interpretação da música clássica/romântica/modernista, justamente porque o texto fenomenológico, baseado em códigos culturais, não é preexistente, mas se configura precisamente a partir de sua ação. $^{18}$

O âmbito eletivo da extemporização está na produção de um enunciado musical que não tem referente escrito, ou com referente escrito a partir do qual seja possível, por convenção cultural, se afastar performativamente, passando a afetar a própria estrutura ritmo-diastemática, harmônica ou modal, etc. sem perder a identidade textual de unidade de conceituação musical e fluir em um procedimento variacional-elaborativo intencional e culturalmente reconhecido. Recordo que nessas dinâmicas criativas é crucial a presença de critérios relativos aos conceitos da estética

\footnotetext{
18 Até mesmo o autor da canção pop mais simples espera com a respiração suspensa o momento de ouvir a gravação de sua própria música para saber a verdadeira forma de sua composição, que é outra coisa em relação à revelação que vem da interpretação, da Reproduktion (Adorno), da composição de tradição culta. O processo de constituição de tal forma, que envolve níveis concretos operacionais sintáticos do material, é conferido propriamente pelos processos extemporizativos por meio da inscrição da formatividade audiotátil dos diversos atores musicais no dispositivo de gravação (o que o cantor realmente cantou, quais arpejos o guitarrista terá tocado, quais inversões de acordes o pianista terá utilizado e com que articulação rítmica, a relação entre caixa e bumbo etc., além da interação sensóriomotora de todos esses fatores e sua projeção no design sonoro em pós-produção). Todos esses aspectos de elaboração formal não preexistem à projeção extemporizativa, não são predeterminados e - na medida em que são dependentes da formatividade idiossincrática dos atores individuais (incluindo o sound engineer) - predetermináveis (no caso da gravação sonora, são ativos os fundamentais processos estéticos que eu defino como neoauráticos). Cf. Caporaletti (2005, p. 121 et seq.).
} 
ocidental moderna que mencionei acima, de modo que mesmo os casos de variação de repertórios e práticas de culturas tradicionais se enquadrariam nesta categoria.

Em termos da teoria da informação, a extemporização pode, portanto, ser definida com base na taxa de informatividade presente no processo executivo, ou seja, ao grau potencial de escolhas possíveis. Este conjunto de possibilidades é diferente no grau e na substância (quantidade e qualidade) em relação àquele condicionado pela adesão ao control object composicional na música de tradição escrita ocidental clássica/romântica/modernista.

É desnecessário dizer que a improvisação propriamente dita - como primeira aproximação, mas aqui remeto mais ainda a Caporaletti (2005, p. 116 et seq.) - manifesta-se por meio de uma elaboração construtiva de segundo nível que se distancia desse substrato extemporizativo, sujeita a convenções culturais tanto na articulação formal quanto nos próprios valores estéticos - geneticamente, da modernidade ocidental - que a identificam.

\section{Transposições didáticas}

À luz dos argumentos até aqui apresentados no plano epistemológico, devemos agora nos questionar sobre o problema das concretas estratégias (ou, seguindo Chevallard, transposições) didáticas em relação ao ensino das práticas improvisativas, de modo a passar do savoir savant ao savoir enseigné. A elaboração de um manual de técnica improvisativa foge ao escopo desta discussão: preferivelmente, serão dadas indicações gerais de modo a constituir as diretrizes de um possível currículo.

O conjunto desses critérios metodológicos, que denomino abordagem audiotátil, se orientará prioritariamente na direção da implementação dos valores processuais (em oposição aos valores estruturais, que em todo caso só serão reinseridos posteriormente) que vimos caracterizar os esquemas de ordem cognitivos, tão importante na experiência improvisativa. Este fator processual deve desempenhar um papel fundamental desde os primeiros estágios da didática da improvisação: ele é imprescindível se o objetivo é fazer com que o aluno experimente o sentido profundo 
e o significado bem específico da criatividade em tempo real, de modo que haja uma participação mesmo nos níveis mais elementares dos resultados e valores que marcam essas experiências na pesquisa artística madura. E isto, repito, independentemente de competências baseadas na aquisição de elaborados conteúdos teóricos, de estruturas abstratas: portanto, com meios e procedimentos completamente elementares.

O primeiro elemento a considerar nesta comunicação e revelação do processo é a interatividade criativa. É preciso evitar que as experiências criativas em tempo real resultem em uma prática solipsística que remeta a outros modelos poiéticos, mais próximos da composição da tradição escrita ocidental. Tocar inventivamente junto com outros alunos, e sobretudo com o professor, se revela um elemento de absoluta relevância para internalizar o sentido de um processo que se dá em uma temporalidade intencional e irrevogável (e não em um tempo recipiente congelado em que se organizam sintaticamente - sempre com base na reversibilidade temporal identificada por Piaget: lembro que devemos ter em mente esse fator de maturação cognitiva nas crianças mais novas - as estruturas teóricas).

Um corolário desta abordagem básica é a promoção no aluno da reatividade aos estímulos sonoros - em referência aos timbres, a agrupamentos rítmicos, a características semânticas do som, peculiaridades sensório-motoras, fônica articulatória, etc. -, a ser solicitado de várias formas, no modelo linguístico da proposta-resposta: com instrumentos musicais ou com o uso da voz (não é necessário, nesta fase, o domínio de uma técnica, nem a observância da restrição métrica, experiência com práticas de exploração instrumental ou vocal). Na escola primária, será cuidado para que essa resposta seja fisicalizada, ou seja, autodirigida pelo movimento corporal (com exercícios de imitação/transformação de determinadas sequências motoras - rítmicas ou não - propostas pelo professor e entre os próprios alunos). O objetivo primordial dessa fisicalização traçada pelo medium corporal é a afirmação consciente de valores sensório-motor-afetivos típicos dos esquemas de ordem na interação reativa explorada nesta fase preparatória.

Um elemento cardinal, tanto para esta fase quanto para as subsequentes no processo didático, é o uso consciente da gravação (vídeo)sonora para obter a fonofixação das várias práticas criativas. Este dispositivo de inscrição do princípio 
audiotátil no suporte gravado tem a função de incentivar e direcionar as faculdades críticas, além de constituir em si um fator de objetivação de uma experiência de outra forma fenomenologicamente evanescente e não datada, portanto, de um estatuto ontológico substancial. Essa etapa corresponde, no plano pedagógico-didático, à função da categoria de codificação neoaurática na economia da teoria audiootátil: um aspecto fundamental para identificar o proprium dos fenômenos improvisativos e das músicas audiotáteis em geral.

Após esta fase exploratória, intervém o primeiro critério pedagógicodidático inerente aos processos de criação em tempo real, relativo à função extemporizativa. É uma passagem de grande importância que eu gostaria de tornar objeto da maior atenção. Vimos como, no nível teórico, há uma gradação operacional entre extemporização e improvisação propriamente dita; ora, essa gradação deve necessariamente estabelecer homologias metodológicas na transposição didática. Gostaria também de enfatizar que este fator por si só constitui uma inovação também nas metodologias avançadas de didática da improvisação musical. Para efeitos pedagógicos, podemos assumir com segurança o critério da complexidade como principal fator comensurativo desta gradação, entendido como "a soma de um índice de heterogeneidade da forma e dissimilaridade dos elementos" (NATTIEZ, 2004, p. 53). Em certo sentido, é a passagem do mais simples ao mais complexo, para o qual o processo de extemporização é um pressuposto incontornável para o estabelecimento de habilidade improvisativa.

Como, então, preparar estratégias adequadas para a aquisição de habilidades extemporizativas? Este ponto é muito delicado e envolve uma mudança de crenças e modelos de funcionamento profundamente enraizados na mentalidade pedagógica (mas não apenas) musical. Definimos extemporização como o processo primário de constituição textual em tempo real, consistindo na realização imediata instanciação - de um modelo musical não escrito, mas de natureza imaginativa, por meio de estratégias poiéticas adequadas (ver Fig. 3). Ora, a aquisição de habilidades relativas a este processo, das formas mais simples às mais complexas, deve exatamente constituir o objetivo da prática didática neste nível. 
De fato, estamos aqui a afirmar, com bases rigorosas, o valor pedagógico de uma metodologia de ensino musical que prescinda, na produção de um texto musical, da execução e da própria referência a uma partitura prescrita na notação convencional, mas que se baseie, ao invés disso, em uma série de habilidades poiéticas baseadas no modelo cognitivo audiotátil, na racionalidade idiossincrática da articulação digitalmotora ou fonatória combinada com - e orientada por - feedback de controle da percepção auditiva. E não estou me referindo à capacidade óbvia de produzir improvisações, o que pressupõe independência da partitura de uma forma que o bom senso aceita e valoriza. Em vez disso, refiro-me à simples produção de um texto musical fechado, uma peça pop, por exemplo, feita com procedimentos que prescindam da leitura musical.

Como é facilmente intuível, é algo muito diferente de improvisar, correspondendo, de fato, àquela produção em tempo real de um tipo extemporizativo muito diferente da improvisação, mas que, no entanto, constitui a sua etapa formativa preliminar, tanto no sentido pedagógico como em um nível artístico. Acredito que, no estudo da improvisação musical, as maiores dificuldades encontradas pelos alunos, mesmo tecnicamente avançados, muitas vezes detentores de diplomas de graduação em instrumento, podem ser atribuídas ao fato de a aquisição de competências extemporizativas serem omitidas ou subestimadas no percurso de aprendizagem, pretendendo-se atingir diretamente o nível improvisativo. Mas essa consciência também está faltando na maioria dos manuais didáticos e tratados teóricos, que, como vimos, partem diretamente do estudo de estruturas teóricas abstratas do contexto da temporalidade intencional, provavelmente implicando que esse domínio da forma vetorizada no devir, essa projeção do PAT na dimensão da grande escala temporal, diríamos nós, seja uma competência já adquirida.

Mas qual pedagogia orienta essas aquisições e com quais modelos operativos? Responder a esta questão evocando o "conhecimento tácito" significa evitar a questão e, sobretudo, excluir o enquadramento do problema da criatividade em tempo real dentro de um currículo racionalmente preparado. Esse fato, entre outras coisas, interferiria dramaticamente, de forma devastadora, no projeto de estudos das 
"músicas improvisadas e audiotáteis", 19 assim como previsto pelas normas conservatoriais vigentes. E então, quais critérios didáticos utilizar? Deve-se, talvez, prescindir do estudo de solfejo e da leitura musical na abordagem instrumental? Claro que não, mas é preciso acompanhar estas aquisições de códigos epistemologicamente visuais - que esteja claro - totalmente adaptados e funcionais não apenas à literatura histórica da música culta ocidental - também as apropriações de códigos incorporados, de habilidades audiotáteis, que conduzam o aluno, com graus e formas a serem estabelecidas de tempos em tempos, para a realização de um duplo conjunto de competências e habilidades, de matriz epistemológica visual e audiotátil. E isso, como já observamos, também considerando o fato de que, em uma prática audiotátil madura, as habilidades de leitura e de conhecimento teórico em geral são normalmente subsumidas pelo modelo cognitivo prevalente.

Para um primeiro exemplo de estratégia didática, voltada para a aquisição de habilidades extemporizativas, vou me referir às aulas de instrumentos musicais na escola secundária, pressupondo um grau razoável de domínio instrumental. A técnica a ser utilizada, por exemplo, com instrumentos de vocação harmônica, como a guitarra ou o piano, consiste na realização de uma peça a partir da estrutura nua de acordes o modelo figural - escrita em siglas (com solmização indiferentemente anglo-saxônica ou italiana). Vamos observar, nesta fase, quais aspectos envolvem a extemporização. Em primeiro lugar, os acordos devem ser realizados com uma escolha de disposição de vozes que já pressupõe um critério articulado de produção em tempo real, especialmente se o aluno é capaz de alternar ex tempore as várias inversões e configurações do mesmo grau harmônico. Mas o aspecto mais importante é a realização rítmica como fator motor e propulsor da música. Este nível pressupõe que o aluno elabore uma estrutura percussiva a partir da grade dos acordes, fazendo escolhas rítmicas e variações, sempre acompanhando o grupo, de forma a não perder o sentido propulsivo da pulsação subjacente (neste aspecto, há questões óbvias de coerência estilística, inerentes ao tipo de peça escolhida). É claro que todo esse processo pode ser configurado propedeuticamente com instrumentos de percussão.

${ }^{19}$ Cf. D.M. 483/07 e seg. 
A partir de uma primeira reprodução aceitável do estilo de execução, podese passar, em seguida, à integração personalizada da peça, com várias mudanças que afetam os diferentes parâmetros sonoros. Essa atividade pode agora envolver o nível ritmo-diastemático monódico, com ligeiras modificações do desenho melódico. Este aspecto é fundamental: o princípio pedagógico a se ter em mente nesta fase é que, a partir da modificação contextual de textos, chegamos gradualmente à invenção formal ex tempore e à introdução de novos materiais numa perspectiva elaborativo-variacional conduzida intencionalmente, característica da dimensão propriamente improvisativa.

Reformular esse percurso para a escola primária significa, essencialmente, prescindir da posse de competências técnico-executivas já formadas. Para manter estável o objetivo da aquisição de faculdades extemporizativas, pode-se recorrer à execução de partituras conceituais "abertas" (o próprio professor pode prepará-las ou utilizar diretamente obras autorais) destinadas a sonorização. Essas elaborações gráficas se constituem como um modelo ao qual a criatividade das crianças é capaz de conferir inúmeras soluções executivas, realizando, a partir de um mesmo control object, textos musicais que de fato não existem na predeterminação escritural (de qualquer maneira, não notacional), senão de forma muito aleatória e sugestiva. O conceito-chave nesta fase é a modificação e a apropriação do texto (seja verbal, seja musical): por exemplo, variando as palavras das canções ou a gestualidade na dança. Deve-se ter em mente que, seja na fase exploratória, seja no estudo e na prática da extemporização, o objetivo de longo prazo é a aquisição de habilidades audiotáteis que por si só são eletivamente personalizadoras. Somente quando este tipo específico de formatividade é adquirido com um grau confiável de competência por parte dos alunos, pode-se afrontar o estudo da improvisação propriamente dita.

No plano estritamente técnico/curricular, a experiência nos sugere que, grosso modo, os objetivos relativos aos dois âmbitos distintos, extemporizativo e improvisativo, possam ser indexados respectivamente nas duas ordens escolares, primária e secundária (exceto para ampliar e integrar a experiência extemporizativa na escola secundária). De qualquer maneira, fica estabelecida a aplicação, aos dois ciclos, das metodologias que promovam e potenciem as competências postas em prática, seja pela extemporização, seja pela improvisação, ou seja, estratégias 
formativas para o controle temporal, para aquisição de competências fraseológicas baseadas na simetria métrica, ${ }^{20}$ para a discriminação auditiva melódica e sobretudo harmônica, para a identificação dos efeitos sensório-motores do swing e do groove e de suas declinações específicas. $O$ todo, prescindindo tanto quanto possível da abordagem notacional e/ou da leitura musical.

Neste ponto, o estudo da improvisação será o êxito natural de muitas habilidades já adquiridas, no sentido da orientação no campo auditivo e do uso consciente da faculdade extemporizativa. Será possível avançar para a aquisição de competências variacional-elaborativas, introduzindo na construção ex tempore novo material não diretamente relacionado ao substrato extemporizativo, mais orientado na dimensão melódica em oposição à extemporização harmônica (esta distinção é válida, no entanto, apenas em função pedagógico-didática, não identificando uma diferenciação ontológica). É somente nessa delicada fase didática que as estruturas teóricas deverão ser reintroduzidas, cuidando para que a carga teórica não ultrapasse as especificidades audiotáteis, que devem sempre prevalecer.

Não vou me estender aqui na enumeração de técnicas de improvisação e construtos teóricos com os quais operar, a esta altura distribuídos em uma imensa quantidade de manuais especializados em estilos e gêneros. ${ }^{21}$ Quero reservar, contudo, as últimas considerações sobre a natureza do mélos improvisativo. Dentro de uma correta abordagem audiotátil, é essencial entender a mesma articulação fraseológica como um todo orgânico, possivelmente para ser aprendido nos primeiros níveis por pura imitação, mas sem desagregá-la nos primeiros elementos constitutivos, como as escalas ou, pior ainda, as notas musicais. Uma frase improvisativa nasce da necessidade de comunicar, e o gesto ou a fonação traduz essa urgência expressiva em uma totalidade da qual são indistinguíveis os quanta de informação que a compõem, justamente porque esses quanta, na realidade, não existem - isto é, não são traços

\footnotetext{
${ }^{20}$ É necessário para isto seguir as indicações seminais de Émile Jacques-Dalcroze $(1932,1933)$ sobre o valor da orientação ritmo-métrica das habilidades motoras físicas, ainda que evitando os gargalos de uma metodologia excessivamente theory-laden e sobrecarregada de valores visuais como aquela proposta pelo músico e pedagogo suíço.

${ }^{21}$ Uma lista dessas estruturas teóricas e técnicas poiéticas está bem delineada em Damiani (2011; cf. em particular p. 121 et seq.).
} 
perceptivos pertinentes - no ato comunicativo. Eles são gerados apenas como construções de nossa mente, que tenta segmentar a totalidade da energia vital.

Essa consciência é frequentemente desconsiderada ou até mesmo implicitamente negada pela mesma estruturação teórica dos manuais atuais. Por exemplo, geralmente se hipostatiza a presença de estruturas abstratas escalares/modais, mas aqui o problema não é mais apenas o da fungibilidade dessas estruturas no que diz respeito à experiência improvisativa, como já discutimos. A questão ulterior, talvez bem mais grave, é que no plano epistemológico tais estruturas - por exemplo, a concepção escalar/modal que conduz à teorização de construtos, como a escala de blues ou a assim chamada "escala bop" - não estão sujeitas, no âmbito de teoria do jazz, à crítica preventiva sobre sua valência efetiva, que, mediante uma análise cuidadosa, revelaria ser o resultado de um arranjo teórico a posteriori de práticas consolidadas, nascidas da experiência improvisativa vivente. ${ }^{22}$ Que subsequentemente tenham sido engendradas práticas que dependam, por sua vez, destas teorias de jurisdição limitada, a partir dessas "verdades locais", como se diz em epistemologia (para um exemplo nas ciências humanas, seria possível equipará-las ao modelo da "invenção da tradição" de Hobsbawm), ${ }^{23}$ é outro discurso; mas, sobre todo este assunto, e em particular sobre o mal-entendido modal, remando à discussão em Caporaletti (2010).

Quero citar apenas um entre os exemplos mais enganadores, a saber, a recaída didática das ideias (muitas vezes mal compreendidas) de George Russell, ${ }^{24}$ que produziu uma infinidade de manuais, na maioria das vezes baseados em do-it-yourself musical, com base no pressuposto de uma correspondência mecanicista entre escala e acorde. Após um período adequado de condicionamento regulatório a esses preceitos, os estudantes têm a ilusão de frasear com articulações melódicas que ecoam vagamente módulos estilísticos credenciados. Mas o sentido dessas "improvisações" "o que" realmente "se diz" 25 - remanda cada vez mais, infelizmente, ao mundo das

\footnotetext{
22 Observar que esse arranjo a posteriori é um processo que sempre esteve relacionado a toda a teoria musical (ao menos) ocidental e não muda o problema: aqui se trata de experiências audiotáteis, e tal processo, no específico improvisativo, se qualifica de forma problemática.

${ }^{23}$ Cf. Hobsbawm e Ranger (1983).

${ }^{24}$ Cf. Russell (1959).

${ }^{25}$ Cf. Monson (1996).
} 
sensações pré-fabricadas e homologadas da sociedade de consumo forçado e da despersonalização, impostas pelo tecnicismo anti-humanista, pela ditadura do mercado e pelas relações de poder. ${ }^{26}$ Espero, em vez disso, que uma utilização consciente da abordagem audiotátil, voltada não apenas para a formação de futuras gerações de músicos improvisadores, possa contribuir a delinear um renovado modelo de integridade do indivíduo, baseado no espírito crítico e na investigação constante e rigorosa, sobre a autenticidade existencial, da qual, hoje mais do que nunca, se sente a improrrogável necessidade.

\section{Referências}

AZZARA, Christopher D. Improvisation. In: COLWELL, R.; RICHARDSON, C. (ed.). The New Handbook of Research in Music Teaching and Learning. Oxford: Oxford University Press, 2002. p. 171-187.

BALDI, Gabriella; TAFURI, Johannella; CATERINA, Roberto. The ability of children aged 7-10 to structure musical improvisations. Bulletin of the Council for Research in Music Education, n. 153/154, p. 135-141, 2003.

BELARDI, Walter. Poesia e onniscienza. Tecnica e insegnamento nella Grecia arcaica e nell'Iran zoroastriano. In: BELARDI, Walter. Linguistica generale, Filologia e Critica dell'espressione. Roma: Bonacci, 1990. p. 219-236.

BURNARD, Pamela. Bodily Intention in Children's Improvisation and Composition. Psychology of Music, n. 27, p. 159-174, 1995.

BURNARD, Pamela. Task Design and Experience in Composition. Research Studies in Music Education, n. 5, p. 32-46, 1999.

CAPORALETTI, Vincenzo. La definizione dello swing. I fondamenti estetici del jazz e delle musiche audiotattili. Teramo: Ideasuoni, 2000.

CAPORALETTI, Vincenzo. Musica audiotattile e musica di tradizione orale. Musica Theorica Spectrum, n. 7, p. 2-19, genn. 2004.

CAPORALETTI, Vincenzo. I processi improvvisativi nella musica. Un approccio globale. Lucca: LIM, 2005.

${ }^{26}$ Cf. Marcuse (1964). 
CAPORALETTI, Vincenzo. Esperienze di analisi del jazz. Lucca: LIM, 2007.

CAPORALETTI, Vincenzo. La théorie de la musique audiotactile et ses relations avec l'improvisation dans la musique contemporaine. In: MICHEL, P. (ed.). Filigrane: Musique, Esthétique, Sciences, Société, v. 8, n. II, p. 101-128, 2008.

CAPORALETTI, Vincenzo. La forma groovemica di Spinning Plates dei Broken Arm. Per Archi, n. 5, p.135-153, 2010.

CAPORALETTI, Vincenzo. Jelly Roll Morton, la “Old Quadrille" e "Tiger Rag. Una revisione storiografica, (prefazione di Bruce Boyd Raeburn). Lucca: LIM, 2011a. (Con edizione critica delle partiture retrospettive di Old Quadrille e Tiger Rag, dalle registrazioni alla Library of Congress, Washington, 1938).

CAPORALETTI, Vincenzo. Ghost Notes. Issues of Inaudible Improvisations. In: RASCH, R. (ed.). Beyond Notes: Improvisation in Western Music in the Eighteenth and Nineteenth Century. Turnhout, Belgium: Brepols Publishers, 2011b. p. 345-373.

CHEVALLARD, Ives. La transposition didactique. Grenoble: La Pensée Sauvage, 1985 [ed. ampliata 1991].

CZIKSZENTMIHALIY, Mihaliy. The Psychology of Optimal Experience. New York: Harper \& Row, 1990.

DAMIANI, Paolo. L'arte dell'improvvisazione, un sapere nel mentre si fa. In: LA FACE, G.; SCALFARO, A. (ed.). La musica tra il conoscere e il fare. Milano: Franco Angeli, 2011. p. 111-122.

DAVIES, Coral. "Listen to My Song: A Study of Songs Invented by Children Aged 57 Years". British Journal of Music Education, n. 9, p. 19-48, 1992.

DAVIES, Coral. The Listening Teacher: An Approach to the Collection and Study of Invented Songs of Children Aged 5 to 7. In: LEES, H. (ed.). Musical Connections. Tradition and Change. Proceedings of the $21^{\text {st }}$ ISME World Conference in Tampa, FL, Auckland, New Zealand, University of Auckland, 1994. p. 120-128.

DELLA SETA, Fabrizio. Idea-Testo"Esecuzione. In: AFFORTUNATO, T. (ed.). Musicologia come pretesto. Scritti in onore di Emilia Zanetti. Roma: Istituto Italiano per la Storia della Musica, 1994. p. 137-146.

DOWLING, W. Jay. The Development of Music Perception and Cognition. In: DEUTSCH, D. (ed.). The Psychology of Music. 2. ed. New York: Academic Press, 1999. p. 603-625.

FLOHR, John. Musical Improvisation Behavior of Young Children. Dissertation (Ph.D.) University of Illinois at Urbana-Champaign, 1979. 
GARDNER, Howard. Creativity: an Interdisciplinary Perspective. Creativity Research Journal, n. 1, p. 8-26, 1988.

GOODMAN, Nelson. Languages of Art. Indianapolis, New York: Bobbs-Merrill, 1968 [tr. it. I linguaggi dell'arte, Milano, Il Saggiatore, 1976].

HANSON, Norwood Russell. Patterns of Discovery. Cambridge: Cambridge University Press, 1958 [rist. 1975].

HOBSBAWM, Eric J.; RANGER, Terence (ed.). The Invention of Tradition. Cambridge: Cambridge University Press, 1983.

IMBERTY, Michel. Langage, musique et cognition: quelques remarques sur l'évolution nécessaire des problématiques psychologiques des vingt dernières années. Circuit: musiques contemporaines, v. 13, n. 2, p. 93-110, 2003.

JACQUES-DALCROZE, Émile. L'improvisation au piano. Le Rythme, n. 34, p. 3-15, 1932.

JACQUES-DALCROZE, Émile. L'improvisation musicale. Revue Musicale, n. 136, p. 344-358, 1933.

KEIL, Charles. Participatory Discrepancies and the Power of Music. Cultural Anthropology, n. 3, p. 275-284, 1987.

KRATUS, John. Growing with Improvisation. Music Educators Journal, v. 78, n. 9, p. 3540, 1991.

LERDHAL, Fred; JACKENDOFF, Ray. A Generative Theory of Tonal Music. Cambridge: MIT Press, 1983.

MAILARET, Jean-Pierre. Explorations musicales instrumentales chez le jeune enfant. Paris: Presses Universitaires de France, 1997.

MARCUSE, Herbert. One-Dimensional Man: Studies in the Ideology of Advanced Industrial Society. 1964 [tr. it. L'uomo ad una dimensione. L'ideologia della società industriale avanzata. Torino: Einaudi, 1999).

MEYER, Leonard B. Explaining Music. New York: Chicago University Press, (21978), 1973.

MIROUDO, Laurent. La tonalité et la temporalité musicale chez l'enfan. Paris: L'Harmattan, 2000. 
MOLINO, Jean. Expérience et connaissance de la musique à l'âge des neurosciences. In: DARBELlAY, E. (ed.). Le temps et la forme. Pour une épistémologie de la connaissance musicale. Genève: Droz, 1998. p. 253-272.

MONSON, Ingrid T. Saying Something: Jazz Improvisation and Interaction. New York, Chicago: University of Chicago Press, 1996.

MOORHEAD, Gladys Evelyn; POND, Donald. Music of Young Children. Santa Barbara (CA): Pillsbury Foundation for Advancement of Music Education, 1941.

NATTIEZ, Jean-Jacques. Il combattimento di Crono e Orfeo. Torino: Einaudi, 2004.

NETTL, Bruno. Thoughts on Improvisation: A Comparative Approach. The Musical Quarterly, v. LX, n. 1, p. 1-19, genn. 1974.

PAPOUSEK, Hanus. "Musicality in Infancy Research: Biological and Cultural Origins of Early Musicality". In: DELIEGE I.; SLOBODA, J. (ed.). Musical Beginnings: Origins and Development of Musical Competence. New York: Oxford University Press, 1996. p. 37-55.

RUSSELL, George Allan. The Lydian-Chromatic Concept of Tonal Organization for Improvisation, for all Instruments. New York: Concept Publishing Corporation, 1959.

SHEHAN CAMPBELL, Patricia. Learning to Improvise Music, Improvising to Learn Music. In: NETTL, B.; SOLIS, G. (ed.). Musical Improvisation: Art, Education, Society. Urbana and Chicago: University of Illinois Press, 2009.

SWANWICK, Keith; TILLMAN, June. The Sequence of Musical Development: Creativity within Cultural Restraints. British Journal of Music Education, v. 3, n. 3, p. 305339, 1986.

TAFURI, Johannella. Processes and teaching strategies in musical improvisation with children. In: DELIĖGE, I.; WIGGINS, G. (ed.). Musical Creativity. Multidisciplinary Research in Theory and Practice. New York: Psychology Press, 2006. p. 134-158.

Submetido em: $21 / 10 / 2021$ Aprovado em: 03/12/2021 Publicado em: 07/01/2022 